\title{
Q. Can we manage demand in COVID-19 world? A. I don't know
}

\author{
Ian Yeoman ${ }^{1}$
}

Published online: 9 February 2021

(c) The Author(s), under exclusive licence to Springer Nature Limited part of Springer Nature 2021

Previous disruption on international tourism flows was a blip compared to COVID-19. COVID-19 is an event that disrupts the pre-existing state of affairs changing natural, political, financial or technical aspects of a systems. It is a situation which is unfolding and we cannot determine the end. So, at best COVID-19 is chaotic, dynamic and dangerous (Denizci Guillet and Chu Angela Mai 2021).

As Lange (2020) said in Garrow and Lurkin (2021)

In 2020, we've seen everything fall off a cliff. At the worst point in April, two thirds of the world's fleet of aircraft was grounded, $90 \%$ of operations were not happening and even more so for international operations, where it was more like $98 \%$. And we have the latest IATA [International Air Transport Association] estimation of where we will end up at the end of the year, which is around $60 \%$ down or $65 \%$ down on last year.

Many countries are now entering their third lockdown, and international movement of tourists is virtually nonexistent. Some countries in-between lockdowns have seen the revival of domestic markets, but these revivals have been the cause of further lockdowns because of the movement of people. It's as if tourism as the global industry and aviation as the means of mobility was the vector that has caused COVID-19 spikes. So, until COVID-19 disappears from this planet through herd immunity or vaccination-we have to presume this is the new norm. Airlines have responded with diligence, providing the necessary infrastructure to keep trade going with a focus on cargo and repatriation flights. The tourist from an aviation perspective has changed the booking period to ten days before departure, wants a flexible ticket, a refund mechanism and is visiting friends and

Ian Yeoman

ian.yeoman@vuw.ac.nz

1 Wellington School of Business and Government, Wellington, New Zealand relatives (Yeoman 2020) rather than leisure travel per se. Business travel is now confined to zoom.

The challenge for Revenue Management and Pricing is 'what is the future and relevance'. As Stomph (2020) says:

We need to reinvent the way we look at bookings or revenue management. The demand curves we used in the past [are not relevant today] and our machine learning algorithms [are not forecasting well] because the data they were trained on are no longer valid because [our historic data are] from a different era.

Thus, change is happening. What Vinod (2021) advocates is a more adaptive approach to Revenue Management that relies less on history but adapts to using up to minute monitoring of key performance indicators that are local to destinations and circumstances. Vinod (2021) suggests a focus on continuous demand management which calls for putting processes and plans in place that account for variability and to ensure proactive management. Latency results because of slow propagation of information resulting in excessive cycle times for decision making. Qiu (2020) notes this issue with historical date and proposes a zero Displacement cost model as a simplified and flexible model for airlines to manage origin and destination in the post-COVID-19 world.

Maybe the future is a homo sapien rather than $\mathrm{AI}$ as computers can't deal with uncertainty and rapid change. Ruhlin (2020) explains:

For this moment, we believe our analysts can do a better job than the system in this area because there are a lot of variables that we don't capture in our systems, like the number of COVID-19 cases,... different travel restrictions, and schedule uncertainty. The increased reliance on manual intervention was further explained by Ruhlin at United who noted that "even as different waves of resurgence of the Coronavirus come, it's a different behavior that we're seeing among passengers and among governments and their restrictions than it was last time. So things are changing so fast that the systems are having a difficult time keeping up". 


\section{The Future}

What is the future? Basically, it will be different from the past. But this is the role of this journal to invite scientists, researchers and practitioners to publish their ideas on how the theories, practices and process of Revenue Management and Pricing will change in and post COVID-19. So keep reading.

\section{References}

DenizciGuillet, B., and C. Chu Angela Mai. 2021. Managing hotel revenue amid the COVID-19 crisis. International Journal of Contemporary Hospitality Management. https://doi.org/10.1108/ijchm -06-2020-0623.

Garrow, L., and V. Lurkin. 2021. How COVID-19 is impacting and reshaping the airline industry. Journal of Revenue and Pricing Management. https://doi.org/10.1057/s41272-020-00271-1.

Lange, R. 2020. Keynote Speaker-Senior Vice President at Airbus. Paper presented at the AGIFORS 60th Annual Symposium, virtual platform.
Qiu, L. 2020. Zero displacement cost model: A simplified RM model for post-COVID-19 O\&D management. Journal of Revenue and Pricing Management. https://doi.org/10.1057/s41272-020-00260 -4 .

Ruhlin, E. 2020. Managing Director Revenue Decision Support at United Airlines: A chance to reset revenue management practices? . Paper presented at the AGIFORS 60th Annual Symposium, , virtual platform.

Stomph, S. 2020. Vice President at KLM Royal Dutch Airlines. Keynote speaker. Paper presented at the AGIFORS 60th Annual Symposium, virtual platform.

Vinod, B. 2021. An approach to adaptive robust revenue management with continuous demand management in a COVID-19 era. Journal of Revenue and Pricing Management. https://doi.org/10.1057/ s41272-020-00269-9.

Yeoman, I. 2020. Don't leave home-but then go see your country. https://www.newsroom.co.nz/ideasroom/dont-leave-home-butthen-go-and-see-your-country

Publisher's Note Springer Nature remains neutral with regard to jurisdictional claims in published maps and institutional affiliations. 